\title{
STUTCHKA E AS CONTRIBUIÇÕES PARA A CULTURA JURÍDICA SOVIÉTICA REVOLUCIONÁRIA ${ }^{1}$
}

\author{
STUTCHKA AND CONTRIBUTIONS TO REVOLUTIONARY SOVIET LEGAL CULTURE
}

\author{
Ricardo Prestes Pazello ${ }^{2}$ \\ Moisés Alves Soares ${ }^{3}$
}

\begin{abstract}
Resumo: O presente estudo pretende apresentar as contribuições do jurista soviético da primeira geração soviética, P. I. Stutchka, para uma cultura jurídica revolucionária, considerando sua participação como jurista da práxis na revolução russa que, igualmente, concebeu uma teoria jurídica para tal contexto. A partir dela, pôde elaborar o entendimento a respeito das três fases do direito soviético, bem como esboçar uma proposta de usos do direito no período de transição.

Palavras-chave: Stutchka; cultura jurídica soviética revolucionária; direito e marxismo.
\end{abstract}

\begin{abstract}
This paper intends to present the contributions of the first-generation Soviet jurist, P. I. Stutchka, to a revolutionary legal culture, considering his participation as a praxis jurist in the Russian revolution, who also conceived a legal theory for such a context. From it, he was able to elaborate the understanding about the three phases of Soviet Law, as well as to outline a proposal of uses of the law in the transition period.
\end{abstract}

Keywords: Stutchka; revolutionary Soviet legal culture; Law and Marxism.

\section{Introdução}

A revolução de outubro de 1917 é fonte de grandes lições para o pensamento marxista, em geral. Para o pensamento jurídico marxista, então, remanesce como imposição

\footnotetext{
${ }^{1}$ Artigo submetido em 05/04/2020 e aprovado para publicação em 16/05/2020.

2 Professor do Curso de Direito e do Programa de Pós-Graduação em Direito da Universidade Federal do Paraná (UFPR). Doutor em Direito das Relações Sociais pelo Programa de Pós-Graduação em Direito da Universidade Federal do Paraná (PPGD/UFPR). Mestre em Filosofia e Teoria do Direito pelo Curso de PósGraduação em Direito da Universidade Federal de Santa Catarina (CPGD/UFSC). Bacharel em Direito pela UFPR. Pesquisador do Núcleo de Direito Cooperativo e Cidadania (NDCC/UFPR), do Núcleo de Estudos Filosóficos (NEFIL/UFPR) e do grupo de pesquisa Direito, Sociedade e Cultura (FDV/ES). Pesquisador e conselheiro do Instituto de Pesquisa, Direitos e Movimentos Sociais (IPDMS), do qual já foi Secretário Geral (2012-2016). Coordenador-geral do Centro de Formação Milton Santos-Lorenzo Milani (Santos-Milani). Membro do Conselho de Representantes da Associação dos Professores da Universidade Federal do ParanáSeção Sindical do ANDES-SN (CRAPUFPR), do qual já foi Presidente (2015-2017), tendo sido também Diretor Jurídico da APUFPR-SSind (2013-2015). Coordenador do projeto de extensão popular Movimento de Assessoria Jurídica Universitária Popular - MAJUP Isabel da Silva, junto à UFPR. Colunista do blogue assessoriajuridicapopular.blogspot.com.br e do jornal Brasil de Fato. ORCID: https://orcid.org/0000-0002-99610583.

${ }^{3}$ Doutor em Direito do Estado pelo Programa de Pós-Graduação em Direito da Universidade Federal do Paraná. Mestre em Teoria e Filosofia do Direito pelo Curso de Pós-Graduação em Direito da Universidade Federal de Santa Catarina. Professor integral do Curso de Direito da UNISOCIESC - Joinville. Coordenador do GT Direito e Marxismo do Instituto de Pesquisa Direitos e Movimentos Sociais (IPDMS). ORCID: https://orcid.org/00000002-2251-4788.
} 
de estudo, tendo gerado reflexões e conclusões ainda não superadas, mesmo em contextos e condições geopolíticas bastante distintas. Não pelo fato de que sirva de modelo a se aplicar mecanicamente, mas justamente pelas aberturas que proporcionou à práxis concreta do marxismo revolucionário. Para o campo do direito esta constatação é ainda mais impositva.

A primeira geração de juristas da revolução de 1917 foi o que de mais profundo se pôde alcançar em termos de construção de uma teoria marxista do direito e uma cultura (no sentido da combinação de dimensões materiais e espirituais) jurídica revolucionária. Dentre os seus participantes, as figuras de Stutchka e Pachukanis permanecem como referências as quais precisam ser retomadas e compreendidas, a partir da conjuntura espaço-temporal distinta que lhe sucedeu. Se o segundo dos juristas deixou seu legado em termos de investigação a respeito do ser histórico do direito ligado às relações sociais do capital, o primeiro representa grande esforço de síntese revolucionária, atuando nas várias frentes concretas possíveis em contexto de revolução: direção política, formulação político-jurídica, reflexão teórica e projeção pedagógica. Considerando desse modo o papel de Stutchka, o presente trabalho pretende delinear suas contribuições, notadamente para uma teoria jurídica revolucionária e para uma teoria dos usos políticos do direito. Cem anos depois, suas lições continuam pertinentes e precisam ser resgatadas.

\section{Stutchka, jurista da práxis na revolução russa}

O nome de Petr Ivanovich Stutchka ${ }^{4}$ costuma ser pouco lembrado pela crítica jurídica marxista, em especial pela sombra que o mais eminente dentre os marxistas do direito soviético - Pachukanis - projeta. $^{5}$ Sem dúvida, entendemos que uma teoria marxista do direito tem em Pachukanis seu ponto mais alto, mas isto não deve impedir de conceber a devida importância a um pioneiro em sua elaboração, ainda mais devido a sua representativa atuação na construção bolchevique, inclusive no processo revolucionário russo de 1917.

Stutchka ${ }^{6}$ nasceu na capital da Letônia, Riga, a 14 de julho de 1865, em uma família camponesa e teve a oportunidade de estudar direito na Universidade de São Petersburgo. É neste contexto russo que trava contato com os debates revolucionários, inclusive marxistas,

\footnotetext{
${ }^{4}$ A transliteração do nome russo também pode ser escrita como (Piotr ou Peteris Ivanovitch) Stucka, Stuchka ou Stutschka, dentre outras grafias.

${ }^{5}$ Dentre os poucos estudos específicos, por exemplo, produzidos no contexto da crítica jurídica brasileira, cabe citar Ferreira (2009).

${ }^{6}$ As informações biobliográficas a seguir foram, em sua maioria, retiradas do apenso feito por Umberto Cerroni (1967, p. XLI-XLVI).
} 
tendo conhecido Alexander Ulianov, irmão de Lênin que fora condenado à morte em 1887 por ter participado de grupo de ação direta que pretendia assassinar o czar russo Alexandre III. Formado em 1888, Stutchka retorna a Riga para trabalhar como advogado, mas também participa de círculos intelectuais (políticos e jornalísticos) que se organizavam sob influência de grupo análogo criado por Lênin. Após perseguição política e condenação jurídica, Stutchka se integra à social-democracia, tendo criado o partido letão, em 1904. A partir daí, sempre defender as teses dos bolcheviques, tendo sido integrante do partido que se criaria em 1912. Atuou como advogado dos militantes perseguidos pelo czarismo e, em 1917, integrou o Comitê Executivo do Soviete de Petrogrado como minoria bolchevique no contexto da revolução de fevereiro e, depois, teve vários cargos relevantes no governo revolucionário de outubro.

Dentre as funções revolucionárias mais relevantes, destacam-se o cargo de Comissário do Povo para a Justiça (equivalente a ministro da justiça) entre 1917 e 1918, bem como o de primeiro presidente do governo soviético da Letônia, entre 1918 e 1920. Além disso, foi presidente do tribunal supremo da Rússia soviética e teve outras participações no comissariado para a justiça, bem como atividades políticas e docentes.

Quanto a sua produção, notabilizou-se pela produção jurídica teórica, especialmente com o livro de 1921, A função revolucionária do direito e do estado: teoria geral do direito, em que apresenta uma síntese da concepção marxista a respeito do direito que seria decisiva para os debates no contexto da revolução de 1917. No entanto, escreveu também sobre várias outras áreas do direito, para além de teoria geral, como sobre direito civil e constitucional. Além disso, é de se ressaltar sua tentativa de popularização do debate jurídico junto às massas, com enciclopédias e livros de perguntas e respostas, em linguagem mais acessível, que contemplava questões jurídicas mas também político-revolucionárias. Por outro lado, também se notabilizou pela participação na redação de textos legislativos, em especial os primeiros decretos revolucionários, os princípios do direito penal e os diplomas regulando o funcionamento dos tribunais populares, assim como a constituição da Letônia.

Sua trajetória, assim, revela importância não desprezível no contexto do corpo de intelectuais que sustentaram o processo revolucionário soviético após a tomada do poder. E isto pode ser atestado, aliás, se verificado que Lênin o menciona em alguns discursos, ${ }^{7}$ bem como se corresponde com ele em algumas das cartas conservadas e compiladas nas obras

\footnotetext{
${ }^{7}$ É o que se percebe da menção a respeito de "um telegrama recebido ontem do camarada Stucka" no contexto da luta política na Letônia, em Lênin (1986, p. 338).
} 
completas do revolucionário russo (das que pudemos ter acesso, uma foi escrita por Lênin em 1919 felicitando Stutchka por publicar as obras completas de Rosa Luxemburgo e Liebknecht na Letônia (LENIN, 1988a, p. 300); e a outra é um telegrama secreto de 1921 referido a uma questão de presos políticos na Letônia, para os quais Stutchka pedia auxílio de Lênin [1988b, p. 298]).

Dessa forma, mostra-se incontestável o papel desempenhado no contexto revolucionário soviético, tanto ao nível político quanto teórico e mesmo técnico, pelo jurista que viria a falecer em 1932, o que por si só justifica o interesse por seu papel histórico. No entanto, sua obra é a comprovação ainda mais fiel disso. Em que pese, infelizmente, não podermos realizar uma minuciosa análise da obra de Stutchka em sua totalidade - devido a sua extensão bem como ao fato de nem todos os textos restarem acessíveis - procuraremos delinear dois aspectos dentre os mais salutares de sua produção: uma teoria marxista revolucionária do direito, a partir da periodização feita pelo próprio autor no contexto soviético, bem como uma teoria dos usos do direito no período de transição que o processo revolucionário representou. É o que veremos a seguir.

\section{Para uma teoria jurídica sob o signo da revolução: as três fases do direito soviético}

É no contexto das demandas concretas de reorganização da política e consolidação da ordem imposta por outro bloco histórico que Stutchka alcança papel proeminente no debate a respeito da dimensão assumida pelo direito no processo revolucionário. Stutchka "pertence à primeira geração de juristas que amadurecem no curso do próprio movimento político e não acadêmicos que 'casam' o marxismo com a própria formação intelectual tradicional" (CERRONI, 1976, p. 55). Conjuntamente com Pachukanis, estará entre os juristas soviéticos mais representativos do denominado "lúcido intervalo", isto é, o período de contrahegemonia ao positivismo jurídico em que, com base na necessidade revolucionária de elaborar uma teoria do direito marxista para dar respostas à dinâmica concreta da sociedade em (des)construção, constituiu-se uma teoria geral acerca do fenômeno jurídico orientada, em

\footnotetext{
8 “O governo provisório, ao se encarregar do poder depois da revolução, inaugurou uma era de saneamento da Magistratura, que tem se denominado 'lúcido intervalo’ na vida jurídica Russa” (JIMÉNEZ DE ASÚA, 1947, p. 53). Esse momento de efervescência criativa finda com o avanço progressivo do cerco stalinista. Nesta fase, sob a batuta de Vichinsky, ocorre o retorno ao normativismo e o fortalecimento da tese de um Estado e Direito socialista.
} 
sua totalidade, pelo método marxiano com vistas à extinção dessa forma de mediação histórica do metabolismo do capital.

O próprio Stutchka, no curso de tal "lúcido intervalo", em 1927, não sendo capaz portanto de avaliar a estalinização posterior e a hegemonia de um positivismo jurídico dito revolucionário, delineia três fases do direito soviético após a revolução de outubro: “1) a fase da destruição e do chamado comunismo de guerra; 2) a fase do recuo; 3) a fase do novo avanço em direção ao socialismo com base na NEP ou, para expressar-se em forma jurídica, baseado no direito soviético" (STUCKA, 1967c, p. 450).

Em breves traços, a primeira fase significa a materialização da condição de existência do processo revolucionário frente à guerra civil imposta pela intervenção estrangeira e a necessidade de se reconstruir as instituições para além da velha legalidade burguesa. Por sua vez, o intitulado recuo - "voluntário, meditado e limitado" (STUCKA, 1967c, p. 451) -, referido por Stutchka, consiste na implantação da Nova Política Econômica (NEP), que implica um retorno planejado da forma jurídica capitalista, originando a produção das principais legislações/regulamentações sociais: Código Penal, Código Civil e Código Agrário. Em último lugar, o momento histórico em que o jurista soviético projetava se encontrar era o de uma ofensiva, também no plano jurídico, em direção ao socialismo, cuja expressão seria a construção de um novo direito de transição: o direito soviético.

Nesse sentido, primeira fase inicia-se pela premência de reestruturação do direito, tanto no âmbito formal quanto material, após a vitória revolucionária. Enquanto timoneiro dessa fase de reformulação - pois fora Comissário do Povo para Justiça -, Stutchka encaminha o Decreto $\mathrm{n}^{\circ} 1$, que dispõe sobre uma reforma do funcionamento dos tribunais. Nele consta sobre a vigência da legislação que determina que "os tribunais locais decidem as causas em nome da República Russa e guiam-se, em suas decisões e sentenças, pelas leis dos governos derrubados, apenas na medida em que essas não tenham sido ab-rogadas pela Revolução e não contradigam a moral revolucionária” (STUTCHKA, 2009b, p. 95).

No entanto, a democratização do aparelho jurídico conferindo poder aos sovietes, com o predomínio de uma solução desburocratizada e local ao critério político de classe, não representou a formação de uma crítica marxista do/ao fenômeno jurídico na etapa do comunismo de guerra. Pelo contrário, a invocação de um critério material normativo baseado na "moral revolucionária e a consciência jurídica revolucionária" não implicou que "a concepção marxista revolucionária do direito saiu vitoriosa; não: não podia vencer porque não existia, e acabou sendo vitoriosa a ficção do direito intuitivo" (STUCKA, 1988, p. 114). 
Tal concepção encontra origem, embora alcance vestes vermelhas sob a teoria de Reisner, sobretudo, no pensamento de um jurista pré-revolucionário chamado Petrazitsky. Ao conceber o direito, essencialmente, como um fenômeno ideológico, concebe-se "uma teoria ao mesmo tempo antitradicionalista e aberta às perspectivas de um pluralismo sociológico, como também às de uma resolução do fenômeno jurídico no voluntarismo do grupo (direito intuitivo) e, em última análise, na política” (CERRONI, 1976, p. 48).

O recurso ao intuicionismo de Petrazitsky acaba por conferir, subjetivamente, legitimidade político-jurídica para a aplicação/formação de um direito de acordo com a moral revolucionária. Embora Stutchka assumisse a inspiração contingente desta teoria e suas notórias limitações, ${ }^{9}$ ressalvava que o "conceito de 'consciência jurídica', 'revolucionária' primeiro e depois 'socialista', assumido no curso da revolução, graças à adjetivação adicionada, daria um conteúdo de classe completamente novo e real, que não conserva nada em comum com a 'ideia eterna do direito"” (STUCKA, 1967d, p. 425).

Entretanto, apesar de sua utilidade política e parcialidade teórica - o "Direito Intuitivo" será ressignificado como uma forma ideológica que comporta os interesses de classe posteriormente -, um processo revolucionário, que pretende extinguir as formas de mediação social legadas pela burguesia, necessita de suas próprias armas teóricas. Por isso, Stutchka se põe a trabalhar em uma teoria marxista do direito que busque compreender os traços essenciais do fenômeno jurídico e que aponte para seu definhamento.

Ainda na fase do comunismo de guerra, Stutchka realiza um grande esboço no campo normativo de sua formulação teórica que seria ampliada e desenvolvida em seus escritos posteriores, em virtude da promulgação dos Princípios fundamentais de direito penal da RSFSR de 1919. Esta breve sistematização surge como meio de defender a revolução dos inimigos de classe e contornar as possíveis infrações emergentes da ditadura do proletariado, isto é, busca explicitar, em seu artigo $3^{\circ}$, que o intento desta normatização é "pela repressão proteger o sistema de relações sociais correspondente aos interesses dos trabalhadores organizados enquanto classe dominante na transição do capitalismo para o comunismo durante a ditadura do proletariado" (RUKOVODYASHCHIYE, 2013).

Apesar de o elemento central dos Princípios fundamentais de 1919 consistir no estabelecimento de diretriz para realização do controle social soviético, tal estrutura normativa transcende e muito o âmbito da dogmática penal. Pois, para reestruturar os

\footnotetext{
9 "A escola do dirigente cadete Pretrajiskii poder-se-ia alegrar em virtude de que teríamos acolhido sua concepção referente ao Direito Intuitivo, porém dela divergimos, profundamente, no que concerne à sua fundamentação" (STUTCHKA, 2009e, p. 19).
} 
aparelhos repressivos de Estado, seria indispensável conceituar, com a provisoriedade característica de um tempo de guerra, uma concepção geral sobre a função revolucionária do direito. Assim, transbordando para uma teoria geral do direito, demarcou-se, em seu artigo $1^{\circ}$, que "o direito é o sistema (ordem) de relações sociais que correspondem aos interesses da classe dominante e que são garantidos pelo seu poder organizado" (RUKOVODYASHCHIYE, 2013).

Tal conceito de direito formulado sob a pressão das transformações revolucionárias emerge como uma primeira aproximação "marxista" do fenômeno jurídico, conservando-se como elemento sintetizador, que sua obra principal, de 1921, A função revolucionária do direito e do estado (à edição em português mais divulgada no Brasil deu-se o título Direito e luta de classes), desenvolverá. Nesse sentido, Stutchka afirma que

\footnotetext{
em conjunto considero ainda hoje válida a definição do Comissariado do Povo para Justiça, porque inclui os principais componentes do conceito do direito em geral, e não só do direito soviético. O seu principal mérito consiste em colocar, pela primeira vez, o problema do direito em geral sobre uma base científica, renunciando a uma visão puramente formal e vendo no direito um fenômeno social, que muda com a luta de classes, e não uma categoria eterna (STUCKA, 1988, p. 16-17).
}

A continuidade de tal conceituação do direito significava uma negação do subjetivismo voluntarista de Petrazitsky no que se referia à "consciência jurídica" presente no Decreto $\mathrm{n}^{\circ} 1$, bem como uma crítica ao positivismo jurídico e à possibilidade da conciliação jurídico-normativa das contradições sociais em um direito socialista - socialismo jurídico de Menger ou, até mesmo, um pluralismo/institucionalismo à Duguit. Pois os Princípios fundamentais de 1919 inscrevem o direito como uma forma histórica de mediação social intrinsecamente ligada com a luta/divisão de classes.

Ao analisar a definição de direito ora proposta, pode-se analisar como Stutchka insere o campo jurídico como um dos elementos principais da dinâmica do capitalismo. Observa o direito não como uma forma abstrata ou subjetiva, mas como uma forma específica das "relações sociais", que se vinculam aos "interesses da classe dominante" - não há recursos a interesses públicos/universais, mas a interesses contraditórios de uma sociedade cindida -, sendo tutelado pelo "poder" historicamente "organizado" desta classe representado, em geral, pela forma-estado.

Aprofundando o ponto de partida para uma teoria marxista do direito, o jurista soviético compreenderá as "relações sociais" como a mediação social estabelecida pelos 
trabalhadores no âmbito da produção, como também no das relações estabelecidas de apropriação e troca. Deste modo, "as relações de produção e de troca são as relações primárias, enquanto as relações de apropriação, isto é, as relações jurídicas para não falar das relações morais [...] são unicamente relações derivadas; isto não impede, por outro lado, que desempenhem um papel importante em determinadas condições e em determinados períodos históricos" (STUCKA, 1988, p. 39).

Ao compreender o direito articulado com as transformações materiais da sociedade, observa-se o fenômeno jurídico como uma forma social engendrada historicamente em virtude da divisão de classes estabelecida no âmbito da produção. Essa contradição surgida nos processos produtivos - luta de classes - reverbera nas formas sociais que têm esse elemento como momento predominante. Sendo assim, no âmbito material do direito (conteúdo), os “interesses da classe dominante" assumem um papel fundamental. Mas quando

\begin{abstract}
falamos de interesse de classe, certamente, não nos referimos à simples soma dos interesses individuais; este interesse é antes um elemento que impõe a sua marca à totalidade da luta de uma certa classe. É o foco onde se reflete o interesse vital de uma certa classe. Este interesse existe objetivamente, independente da vontade dos próprios membros da classe, e o grau de consciência que uma classe tem do seu interesse é um fenômeno puramente histórico (STUCKA, 1988, p. 47).
\end{abstract}

Por sua vez, nem de longe há uma identidade do direito ao estado moderno em Stutchka, o "poder organizado" de classe na forma-estado e consubstanciado pela norma positivada é uma das expressões, das mais importantes, sem dúvida, do direito como relação social, contudo, não o esgota, evidentemente. Como diz Stutchka: “O Estado em geral e no seu conjunto, realmente monopoliza a tutela e regularização do direito. Sob este aspecto, falamos, naturalmente, do Estado em geral, e nele incluímos todo o seu aparelhamento, sem excluir sequer o autogoverno local, do qual se procura frequentemente inferir artificiosamente um esquema particular de democracia que se contrapõe ao Estado" (STUCKA, 1988, p. 64).

Outra importante característica do conceito de direito delineado pelo jurista russo, que estrutura a dinâmica entre os componentes anteriores, é o de concebê-lo como um sistema de relações: "em geral, damos o nome de sistema à unificação de diversas unidades num único complexo ordenado e vimos que, neste caso, o elemento unificador é determinado pelo interesse de classe, ou em concreto, pelo tipo de apropriação, de propriedade, que lhe 
corresponde" (STUCKA, 1988, p. 68). Há, portanto, uma construção de uma concepção de direito em movimento articulado em suas formas: relações sociais (econômicas), interesse de classe (ideologia) e poder organizado (estado). Sendo assim, "enquanto em todos os outros sistemas tínhamos um só principio determinante, um centro único (Marx empregava neste sentido o termo francês Pivot), em torno do qual gira todo o sistema, no direito existem dois, ou, mesmo três" (STUCKA, 1988, p. 68-69).

O jurista soviético constrói sua grande obra A função revolucionária do direito e do estado a partir de um método marxiano não restrito à famosa alegoria entre base e superestrutura presente no Prefácio de 1959 (MARX, 2008, p. 45). Embora tal metáfora tenha sido utilizada por muito tempo enquanto justificativa teórica para explicações mecanicistas da relação entre base e superestrutura, Stutchka, desde sempre, não resvala em tais determinismos e formula uma concepção complexa da dialética interna do próprio direito e dele com a sociedade.

É nesta questão que reside a dialética das formas do direito em Stutchka, pois ele trabalhará sua aproximação à totalidade complexa do direito estruturado também com base na Introdução de 1857, de Marx - como Pachukanis também o fará posteriormente, em outra obra germinal, Teoria geral do direito e marxismo. Isto é, não terá uma leitura determinista da dinâmica entre base-superestrutura, uma vez que "Marx e Engels não são pura e simplesmente 'causalistas': procedem partindo do desenvolvimento dialético de tudo que existe" (STUCKA, 1988, p. 75). Desta maneira,

\footnotetext{
é evidente que Marx e Engels davam a palavra 'superestrutura' somente um sentido metafórico e não o sentido estritamente arquitetônico de edifício com diversos andares. Nós, baseando-nos no Prefácio à Crítica, em que Marx contrapõe à propriedade formas específicas de garantia (justiça, política, etc.) podemos dizer que inclui na base o sistema de relações sociais, enquanto expressão jurídica das relações de produção, enquanto que na superestrutura inclui a sua forma abstrata (a lei e a ideologia) (STUCKA, 1988, p. 76-77).
}

O direito, então, compõe-se como um sistema de relações sociais estruturado em três formas/pivôs, sendo uma concreta (a relação econômica) e duas abstratas (lei positivada pelo estado e ideologia jurídica):

\footnotetext{
a forma jurídica concreta da relação, coincide com a relação econômica, enquanto a forma abstrata, proclamada na lei, pode não coincidir e chega frequentemente a diferenciar-se muito da relação econômica. Além disso, existe uma terceira forma que, segundo uma conhecida expressão de Petrazickij, podemos chamar de forma "intuitiva": a "emoção" psíquica interna, que o indivíduo sente nas diversas
} 
relações sociais, o juízo que emite sobre elas sob o ponto de vista da "justiça", da "consciência jurídica interna", do "direito natural" etc., ou, por outras palavras, da ideologia (STUCKA, 1988, p. 79).

Deste modo, o jurista letão pôde observar que, além de o direito não ser um epifenômeno da forma econômica, em determinados contextos históricos há a possibilidade de sua veste estatal ser decisiva na conformação das relações de produção ou até mesmo sua dimensão ideológica levar à (des)legitimação da totalidade social.

É para compreender a interdeterminação dessas formas que constituem a totalidade do direito que Stutchka lança mão do conceito de desenvolvimento desigual presente nos Grundrisse. Pois nos Manuscritos de 1857-58, em termos metódicos, Marx observa que há uma relação desigual entre o desenvolvimento da produção material e da produção espiritual, ressaltando que "o ponto verdadeiramente difícil de discutir aqui é o de como as relações de produção, como relações jurídicas, têm um desenvolvimento desigual. Em conseqüência disso, p. ex., a relação do direito privado romano (nem tanto o caso no direito penal e no direito público) com a produção moderna” (MARX, 2011, p. 62, grifo nosso). Tal "nova escrita' invocada introduz portanto as noções decisivas de contratempo ou de nãocontemporaneidade. [...] Esse anacronismo e contratempo surpreenderão aqueles que se contentam com a rígida 'correspondência' entre infra-estruturas e superestruturas do Prefácio de 1859 à Contribuição à crítica da economia política" (LUKÁCS, 1979, p. 41).

A partir dessa negação do determinismo econômico, Stutchka visualiza que, no interior do desenvolvimento da totalidade histórica, há um desligamento, defasagem, discordância, "relação desigual" e "desenvolvimento desigual" entre produção material e produção artística, entre relações jurídicas e relações de produção - absolutamente aplicável à relação entre as formas abstratas e concreta que o direito possui. Assim, em particular para o fenômeno jurídico, pode-se compreender que "uma formação social concreta não é redutível à homogeneidade da relação de produção dominante. [...] Cada qual tem seu ritmo e temporalidade próprios" (BENSAÏD, 1999, p. 40).

Nesse sentido, a questão é: se toda relação econômica é contextualmente uma relação jurídica, como se dá a relação desigual entre a forma concreta e as duas formas abstratas? Stutchka coloca que "entre elas existe, naturalmente, uma recíproca influência de uma sobre a outra e, como já foi dito, na doutrina a discussão é precisamente sobre a qual delas cabe a primazia". E ele mesmo dá sua posição: "nós reconhecemos uma primazia incondicionada e imediata à primeira [forma concreta]. Esta influi sobre as outras duas formas abstratas, por 
um lado, enquanto é um fato, e, por outro, mediante um reflexo; porém, o seu caráter jurídico depende, apesar de tudo, das outras duas formas, cuja influência pode, por vezes, resultar decisiva" (STUCKA, 1988, p. 80). Entre os momentos do direito, portanto, há uma relação de determinação recíproca, pois se é verdade que é a partir de sua forma concreta que o direito encontra sua funcionalidade na reprodução do capital, também é igualmente real que somente por meio de suas formas abstratas que o capital se realiza nas formas de circulação e apropriação.

Assim concebido o desenvolvimento do direito, então, como uma esfera de mediação social especifica no capitalismo, todas as suas três formas tornam-se complexos singulares com uma autonomia relativa e legalidade própria.

\begin{abstract}
No sistema das relações concretas, esta unidade, este caráter de sistema, é produzido, em parte, em virtude do próprio curso do desenvolvimento econômico e, em parte, em virtude da pressão exercida pelo poder da classe dominante (não só por meio da lei, mas mediante todo o seu aparato). Porém, a própria forma abstrata (II) revela, por meio da codificação, da interpretação etc., a tendência para uma coordenação no sistema particular e específico [...] Por último, também a forma "intuitiva", a ideologia, se configura de um modo sistematizado. Depois que estes três sistemas se constituíram como sistemas, passaram a se influenciar mutuamente entre si (STUCKA, 1988, p. 81).
\end{abstract}

Por esta via, em virtude de sua relação desigual, tais formas do direito podem assumir um caráter de não-correspondência e figurar como momento predominante em determinada temporalidade histórica.

A dialética das formas do direito de Stutchka representa a primeira grande aproximação a uma teoria do direito marxista no contexto da revolução de outubro. E, justamente por isso, seu corpo categorial - a forma concreta e as duas abstratas - está profundamente ligado ao centro nervoso da contradição de classes, variando, embora se assuma a primazia da relação concreta, o pivot dessa articulação conforme a história da luta de classes.

Ao pensar no momento histórico concreto após a publicação de sua principal obra embora estivesse situado no momento por ele denominado de recuo, já visualizava a fase estruturada em torno de outro direito, o soviético -, Stutchka defronta-se com o problema concreto de compreender a respeito das potencialidades e limitações do direito no processo revolucionário. A NEP seria a grande parteira desse novo momento do direito "revolucionário", pois com as contradições geradas pela acumulação de capital de tal "recuo planejado", "não foi mera coincidência que tenha aí surgido o primeiro trabalho - aquele do 
camarada Pachukanis - concernente à teoria do direito burguês como direito baseado sobre o trabalho ou sobre o equivalente. Essa obra, contudo, já sinaliza a passagem à terceira fase, iniciada ao fim do recuo" (STUCKA, 1967c, p. 451). Deste modo, tornou-se, cada vez mais gritante, teorizar sobre como operam as formas do direito com a libertação do poder constituinte popular e qual o horizonte para o direito soviético no socialismo.

O jurista soviético, em primeiro lugar, ressalta que o direito ainda deve ser visto como um direito de classe e, sobretudo, como uma forma social inserida no contexto da luta de classes. O que permite compreender que o direito, embora predominantemente tenha uma função de reprodução do ciclo do capital e uma dimensão conservadora/repressiva por meio de sua forma abstrata, pode ser utilizado em períodos de transformação da conjuntura política relativo à contradição econômico-social em um sentido revolucionário - uma espécie de uso tático do direito, como procuraremos aprofundar mais adiante.

Tal passo não significa o abandono do entendimento da essencial historicidade da forma jurídica, pelo contrário, "se entendemos o direito como sistema de relações sociais sustentado pelo poder de uma classe, devemos concluir que, com o naufrágio deste poder, naufraga também o sistema jurídico" (STUCKA, 1988, p. 85). Nesse sentido, não houve recuo de sua posição original no tocante à necessidade da extinção do direito em geral, quando da superação completa das relações de exploração existentes na sua forma concreta, mas não concorda que, na dinâmica da luta de classes, o papel do direito seja unicamente contrarrevolucionário.

Mas, do mesmo modo, não há uma absolutização dessa função revolucionária, uma vez que Stutchka rejeita qualquer saída reformista no interior do processo de transformação social. "A nossa teoria é completamente contrária [concepções gradualistas dentro do marxismo], pois baseamos a nossa teoria revolucionária no princípio de que não só o desenvolvimento da economia, mas também o do direito, se processa por saltos, isto é, mediante revoluções e não mediante evoluções" (STUCKA, 1988, p. 86). O que há é um uso tático do direito dentro de um processo que pressupõe a tomada de poder e a derrota efetiva do outro bloco histórico dentro do estado em sentido estrito, sendo que tal utilização do direito-lei é instrumental para a consolidação da derrota no campo ideológico e igualmente importante para regular e impulsionar o movimento de transformação na esfera produtiva.

Ao analisar tais teorias reformistas expressas pelo socialismo jurídico em seu tratamento das virtualidades "revolucionárias" do direito como o campo privilegiado da mudança social, visualiza que há uma impossibilidade objetiva de dissolver a forma concreta 
do direito antes da tomada de poder proletário. Pois, "antes da revolução, criar relações sociais proletárias próprias em forma concreta é coisa que não merece consideração, uma vez que pressupõe o fim da propriedade privada, dos meios de produção" (STUCKA, 1988, p. 83). É possível com o poder proletário, portanto, embora subsistam os elementos concretos do capital na esfera da produção e da troca (forma concreta), construir politicamente um direito positivo (forma abstrata I) que engendre novas relações sociais, bem como uma consciência de classe/ideologia jurídica (forma abstrata II) capaz de desconstituir os entraves em direção ao socialismo.

Em A função revolucionária do direito e do estado, Stutchka faz uma análise de conjuntura da situação na dialética das formas do direito, ponderando que

na produção, com exceção do campesinato, não há, ou quase não há, qualquer elemento de capitalismo privado, mas a produção, desse novo tipo, é bastante modesta e as forças produtivas param. Na esfera da troca, subsiste um amplo sistema especulativo que, embora perseguido penalmente pelo direito, conserva sua organização e sua força. Na ideologia, a mentalidade do proletariado é também dominada pelo direito "intuitivo" ou "natural", de cujo jugo só se liberta vagarosamente e não tanto por causa, mas apesar de seu pensamento "jurídico" (STUCKA, 1988, p. 84).

Entretanto, é, justamente, neste contexto que o jurista soviético exorta para a função revolucionária do direito em sua forma estatal - um direito de transição -, de modo que o estabeleça como momento predominante da forma jurídica deste processo de transformação social.

Por esta via, conforma-se um direito de transição, ou seja, há um "grande papel que corresponde ao direito, em todas as épocas de transição, como 'propulsor da história' [...]. Dentro desses limites e nesta acepção podemos falar de um direito-revolução" (STUCKA, 1988, p. 93). Com a tomada de poder e a instauração da ditadura do proletariado emerge, assim, "um novo e potente instrumento: o poder estatal; e o exercício do poder estatal situase, em parte, na própria utilização da lei” (STUCKA, 1967b, p. 503). Então, liberto este poder constituinte proletário, o direito que, essencialmente, “é considerado somente como um elemento contra-revolucionário, como uma espécie de força de inércia que freia toda a revolução. [...] porém, por meio de uma revolução, nasce sempre um direito novo e ele é um dos meios de organização de qualquer revolução: um instrumento de reorganização das relações sociais no interesse da classe vitoriosa" (STUCKA, 1988, p. 87). 
Nesse sentido, a época de transição socialista, em que pese não constitua nova forma de produzir a vida, traz especificidades, pois o velho está a morrer e o novo não está pronto para nascer. Isto é, a época de transição é "uma época de predomínio de uma classe, classe esta constituída pela grande maioria até agora escravizada. [...] Todavia, esta época pelo fato de se caracterizar por uma forma de Estado específica, o ordenamento soviético mostra ser um ordenamento social próprio, característico e que tem um direito proletário, soviético, específico" (STUCKA, 1988, p. 38). Há, portanto, a configuração de uma forma políticojurídica representada por sua forma abstrata, o direito soviético, para desconstrução do mundo do capital, que deve ser reconhecida como "como um direito específico de classe que continuará a subsistir, certamente, modificando-se de forma radical, até a extinção do Estado Soviético" (STUCKA, 1967a, p. 494).

Então, como necessidade de formas transicionais ao socialismo, "tal como em todos os domínios, também no domínio do Direito, a Revolução Proletária cumpre, em primeiro lugar, consciente e irrevogavelmente, a exigência de um autêntico democratismo" (STUTCHKA, 2009c, p. 38). Além disso, “o Direito Proletário é, antes de tudo, a simplificação e a popularização da nossa nova ordem social” (STUTCHKA, 2009c, p. 55). Um direito que "a prática da revolução determinou a sua teoria e ideologia: a propriedade estatal dos meios de produção (incluindo a terra) e transporte, o monopólio dos meios de troca" (STUCKA, 1967c, p. 453). O momento de transição, desta forma, engendra uma reestruturação geral dos aparelhos de estado (forma e conteúdo), que é expressa em uma nova legalidade imposta pelo poder soviético.

Há, claramente, um uso tático do direito, em especial em sua forma abstrata, objetivando constituir uma legalidade revolucionária sustentada nas diretivas políticas do partido bolchevique. Era central, para Stutchka, dentro de um contexto de tanta fragmentação territorial e ideológica, a construção de uma unidade política em torno das decisões tomadas pelo governo comunista e, para tanto, ainda que de forma instrumental, seria necessário unificar a palavra de ordem "revolução e lei revolucionária". Por este motivo, aqui, "o cerne do problema não se trata de uma rápida extinção da lei e do direito, mas sim de possuir uma legislação revolucionária” (STUCKA, 1967b, p. 504). A legalidade, portanto, não figura como um obstáculo à transformação social, uma vez que "a revolução procede como uma ditadura que está sob a hegemonia do partido proletário e a ditadura do proletariado opera através da legalidade revolucionária” (STUCKA, 1967b, p. 510). Não há ilusão, em síntese, de que por reformas jurídicas progressivas o socialismo seria alcançado, contudo Stutchka 
ressalta a importância tática que a forma do direito (lei) pode assumir em determinados contextos para reestruturar a produção - sem dizer os mecanismos de apropriação e troca característicos da mediação jurídica -, bem como delinear uma estrutura de controle social e defesa da revolução.

Ao contrário de Pachukanis (1951, p. 252), portanto, que enxergaria, "não obstante as armadilhas da fraseologia revolucionária, a defesa de um direito proletário como essencialmente conservadora", para Stutchka, o horizonte de legitimidade da utilização do direito estaria, nos termos de Negri (2002), no conteúdo delineado por um poder constituinte revolucionário, que construiria, sem o pudor das adjetivações, um direito proletário - um poder constituído não absolutizado - destinado a regular o período de transição socialista. Um "Direito Proletário enquanto Direito de classe sem maquilagem. No grau mais extremo, ele é um Direito revolucionário, que, de nenhuma forma, levanta pretensão existencial maior do que a de um período de transição. Ao mesmo tempo, com o perecimento do Estado de classes morre também o Direito de Classe Proletário e todo Direito de classe em geral" (STUTCHKA, 2009d, p. 78). Não há dúvida de que se encontra certa fraseologia revolucionária na proposta de Stutchka - o próprio categoriza a lei soviética, ressaltando seus aspectos de luta ideológica, em "leis-diretivas" e "leis-palavras de ordem" (STUCKA, 1967a p. 497) -, contudo, em nenhum momento, abre espaço para a ideia de uma perenização de um direito socialista sob o manto do normativismo, pelo contrário, o ponto central é sempre abordar as possibilidades de um uso tático/revolucionário do direito num contexto de construção do socialismo, talvez, abrindo espaço para se tematizar a inconclusa tarefa de teorizar a respeito de um direito insurgente, no sentido de uma teoria dos usos táticos do direito.

\section{Por uma teoria dos usos do direito no período de transição: sobre o direito revolucionário e seus análogos}

Na visão de Stutchka, até pelos cargos que chegou a ocupar, inclusive como dirigente máximo na Letônia, o problema jurídico impunha uma teoria do direito de transição proletário, da classe trabalhadora, relativo ao processo revolucionário vivido na Rússia. Daí seu livro clássico de 1921 chamar-se Função revolucionária do direito e do estado. Ainda que ele venha, com apontamos acima, a aceitar o horizonte da extinção do direito, este se subordina à finalização do processo revolucionário, ou seja, ao alcance da fase superior da 
sociedade comunista: "no dia em que a revolução tiver vencido definitivamente, produzir-seá também o processo de extinção do governo operário e camponês dos Estados e do próprio direito proletário, entendendo o direito no seu significado antigo" (STUCKA, 1988, p. 128). Assim, Stutchka esteve mais preocupado com a construção de um direito durante o apósrevolução, por força das circunstâncias, e aí se encontram suas contribuições e igualmente seus limites para a interpretação marxista do direito.

A partir de sua contribuição para uma teoria do fenômeno jurídico que, como dissemos acima, tem a ver com relações sociais (afastando da teoria marxista do direito, desde logo, as concepções tipicamente burguesas, baseadas em elementos aparentes como normas ou decisões jurídicas), vale a pena ressaltar sua contribuição daí decorrente, qual seja, a complexificação de sua análise acerca do direito a partir de suas formas. No fundo, Stutchka faz uma abordagem eclética do direito, pautada na dicotomia concreto-abstrato. Tal dicotomia, como já avistamos, é muito importante porque fixa o critério determinante para uma análise marxista do direito, ainda que, ao mesmo tempo, coloque o acento diferencial do direito em suas dimensões abstratas. Assim, haveria uma forma concreta do direito, a relação econômica, enquanto que também duas formas abstratas, a lei e a ideologia.

No texto de 1921, portanto, Stutchka escreve que a "contraposição inconfundível" existente entre formas concreta e abstratas é uma "característica de todas as relações jurídicas" (STUCKA, 1988, p. 78). O ponto de partida é a relação concreta, a qual "coincide com a relação econômica" e, neste ponto, pretendia o autor chamar a atenção para sua pressuposição do materialismo histórico. Quanto a isto, Stutchka queria dizer que o direito não se tratava de fenômeno meramente superestrutural, angariando posição na própria estrutura de produção - uma grande contribuição em face da posterior vulgarização do marxismo. Ocorre, porém, que este ponto de partida convive bem com as formas abstratas do direito, que decorrem dos pontos de vista normativo-positivista e psicologista, com forte influência no contexto do pensamento jurídico eslavo - e tudo isto é imprescindível de ser remontado para sugerirmos uma teoria dos usos do direito no período de transição. "A forma abstrata, proclamada na lei, pode não coincidir e chega freqüentemente a diferenciar-se muito da relação econômica" (STUCKA, 1988, p. 79), dizia. Aqui, logo vemos, aparece a legalidade, com relativa autonomia em face da relação econômica, complementando-se com a forma ideológica ou intuitiva, relacionada a "justiça", "consciência jurídica interna" ou “direito natural”, algo pouco explorado na tradição marxista de análise do direito. 
Como já sugerido, a especificidade do direito para Stutchka se encontra na dialética entre concreto e abstrato e não precisamente na forma concreta, apesar de ele formular que "nós reconhecemos uma primazia incondicionada e imediata da primeira", vale dizer, da relação econômica. A primazia incondicionada e imediata, entretanto, se dá através e não por meio do método de Marx, especialmente considerado em $O$ capital. Ainda que devamos reconhecer a criatividade de Stutchka, é preciso observar que sua "dialética" não aponta para a essência do direito como relação jurídica, mas ao contrário, coincide fenomenicamente com ela, a ponto de afirmar que "qualquer relação econômica [...] é contextualmente uma relação jurídica" (STUCKA, 1988, p. 80). Dois problemas, por conseguinte: perdidas de vista foram a essencialidade e a especificidade da forma jurídica.

$\mathrm{O}$ direito se funda na relação econômica - e isto deve ser reconhecido como um avanço stutchkiano para a análise do fenômeno jurídico. No entanto, a crítica que posteriormente Pachukanis lhe faria adquire todo sentido; Stutchka, apesar de mencioná-la na terceira edição de seu livro, escrita 1924, não a aprofunda nem a responde a contento. O problema é basear o direito na dicotomia concreto-abstrato, como se lei e ideologia não tivessem concretude ou a relação econômica não comportasse dimensões abstratas. A nosso ver, apenas o método que considera aparência e essência poderia resolver essa questão (Cf. PAZELLO, 2014, p. 130 e seguintes). O que Stutchka chamou de forma abstrata pode ser considerada como uma forma aparente do direito, fundada em relações sociais de produção, faltando-lhe, portanto, o que lhe é essencial (ou seja, a essência da forma social jurídica) que não coincide com a relação econômica, pura e simplesmente.

Não à-toa, Stutchka se concentra na "função revolucionária" do direito, mesmo que o direito não seja revolucionário por si só. Sua preocupação o leva a centrar toda sua atenção nas aparências que o direito comporta, sob a feição de um "uso revolucionário", o que caracteriza sua teoria do direito de transição proletário. Assim, a importante tarefa da transição pós-revolucionária faz Stutchka esforçar-se em esvaziar a legalidade de seus conteúdos capitalistas e criar um direito do proletariado. Nesse sentido, contribui com uma análise, ainda que pequena, do capítulo VIII, de $O$ capital, no que toca à legislação operária, ${ }^{10}$ sob o capitalismo. Também fornece significativo auxílio ao aparelho de estado e

\footnotetext{
${ }^{10}$ Para ele, "Marx mostra como as tentativas individuais para conseguir uma redução da jornada de trabalho preparam o terreno para transformar este acontecimento em direito sancionado juridicamente nos vários ramos da produção, e ressalta o alcance revolucionário que a sua atuação assumiu em determinado país (e em todo o continente). [...] Transferindo estas conclusões para outra situação revolucionária, que atualmente não nos agrada, mas que, apesar de tudo, foi necessária, por exemplo, na época do surgimento da propriedade privada da
} 
de direito, com a redação do decreto $\mathrm{n}^{\mathrm{o}}$ 1, de 1917, sobre os tribunais, que visava a "abolir as instituições de tribunais em geral” e substituí-las por tribunais populares eleitos, tornar "suspenso o decurso de todos os prazos" e extinguir inclusive "a advocacia privada e juramentada" (STUTCHKA, 2009b, p. 93-96). Com isso, fica mais do que evidente sua preocupação prática com a dimensão judicial e, sobre tal questão, ele se pronunciou dizendo que referido decreto "conseguiu eliminar o direito burguês na Rússia" ainda que recebesse resistência dos "companheiros mais conscientes", pois "enquanto na mente dos revolucionários triunfava a concepção burguesa do direito, nos fatos vencia a revolução" (STUCKA, 1988, p. 114).

Stutchka escreveu seu livro muito tempo antes da ascensão de Stálin e sua proclamação acerca de uma suposta eliminação do direito burguês na Rússia não deve ser reputada a outro motivo senão o de que, para ele, a lei era uma forma do direito, em nível abstrato. Toda essa problemática influencia diretamente o entendimento que Stutchka tem do processo de transição revolucionária no que tange a suas conseqüências para o direito.

Em vários momentos, explicitamente, refere-se ao problema da transição e sua relação com o direito. É preciso dizer, antes de mais, que sua ótica de análise pressupõe o processo revolucionário de tomada do poder político por parte da classe trabalhadora. Aqui, portanto, há uma remissão aos movimentos de massa: por não se tratar de elemento de caráter "evolucionista", temos que "a passagem de um período histórico (de um período de desenvolvimento econômico) para outro" (STUCKA, 1988, p. 75) se dá de modo "revolucionário", quer dizer, implica uma "luta radical" que se consubstancia em "guerra civil” (STUCKA, 1988, p. 43). No entanto, precisamos notar que Stutchka se refere às menções feitas por Marx, em $O$ capital, sobre esta guerra civil no seio do capitalismo; daí serem suas indicações relativas à "sociedade burguesa" qualificada como uma "sociedade em guerra civil permanente (ininterrupta)" (STUCKA, 1988, p. 46). Em outro lugar, todavia, se refere ao período posterior à tomada do poder, pelos bolcheviques, e diz que o "tribunal revolucionário é uma instituição da época de transição" e que "sua atividade depende da dinâmica do movimento social" (STUTCHKA, 2009e, p. 26). Aqui, está sedimentada uma perspectiva que compreende os usos do direito, de maneira tática, a partir já do período prérevolucionário. Não por acaso, Stutchka é considerado um autor da crítica jurídica marxista que se distingue "pela ênfase na luta de classes", a partir da qual "o direito se relaciona com o revolucionário igual ao da legislação operária, ainda que noutra direção" (STUCKA, 1988, p. 94-95). 
poder" (MASCARO, 2009, p. 46-47). Por ter voltado suas preocupações para entender o uso tático (antes da revolução) ou revolucionário (após a tomada do poder) do direito, Stutchka desempenha o importante papel do trabalho concreto com o direito, servindo de alerta a qualquer práxis relativa ao problema jurídico por parte de quem se posiciona desde um ponto de vista marxista. O direito, portanto, precisa ser visto também a partir de seus usos, sob pena de perdermos capacidade de intervenção na realidade concreta (ainda que o debate sobre a essência do direito não possa, igualmente, ser descurado).

A chave analítica para compreender os usos políticos do direito é o processo de transição, em sua especificidade para levar (já que transita) ao comunismo, ou seja, a ruptura revolucionária. Inegavelmente, Stutchka trabalha com estas lentes, contribuindo para uma leitura mais prática da relação entre direito e luta de classes.

Sem dúvida, apesar de Stutchka não ter mais que um horizonte tático para o uso político do direito, sua preocupação não é com a extinguibilidade do fenômeno jurídico, mas sim com sua utilização mesma. E de que forma aparece o direito sob este prisma? Enumeremos: basicamente, como um "direito novo", um "direito de transição", um "direito revolucionário", um “direito soviético", um "direito proletário" ou um "direito de classe".

Procede ele, inicialmente, a uma generalização: "por meio de uma revolução, nasce sempre um direito novo e ele é um dos meios de organização de qualquer revolução" (STUCKA, 1988, p. 87). A frase é ambígua e abstrata, e merece uma consideração crítica. Com esta formulação, há uma dupla generalização que diz respeito à persistência do direito e à tônica revolucionária baseada no direito. O direito novo, que por conta da revolução já não é o mesmo que o direito burguês, se concilia com uma fórmula geral de transição. Esta formulação antecipa em um parágrafo o capítulo VI de seu livro de 1921, intitulado "Direito e revolução". Neste, Stutchka estabelece a importância do "direito, em todas as épocas de transição, como "propulsor da história"” (STUCKA, 1988, p. 93). Aqui, uma vez mais, precisamos lembrar o significado do direito para ele, em consonância com a totalidade das três formas jurídicas, uma concreta e duas abstratas. Se se modifica a relação econômica, muda também o direito, pois elas são coincidentes. O mesmo vale para a forma abstrata representada pela lei: o direito é um sistema de relações sociais que se estabelecem no interesse da classe dominante (e, ressaltemos, se não houver classes, não há mais direito), mas dentro desse interesse cabem a forma ideológica e a forma legal: "teoricamente, a lei deve proporcionar o princípio fundamental (por exemplo, da propriedade privada feudal ou capitalista) e, possivelmente, uma definição clara, exaustiva e suficientemente concreta das 
principais instituições jurídicas" (STUCKA, 1988, p. 126). ${ }^{11}$ Sendo assim, o direito poderia ser uma mola propulsora porque coincidiria com as relações de produção, como já vimos, mas instaura também o aspecto pedagógico a partir do texto legal (princípios e institutos jurídicos).

Ainda no capítulo sobre a relação entre direito e revolução, Stutchka refere-se a um "direito de transição", que se caracterizaria por tornar possível "a abolição completa de toda a exploração em geral", o que se diferencia de "reformas jurídicas que se restringem a mudar somente a forma e o modo de exploração" (STUCKA, 1988, p. 95). Aqui, o uso tático do direito parece ganhar definitivos traços de uso estratégico e a censura Bilharinho Naves a respeito do juridicismo na análise da transição passa a fazer sentido, ocorrendo uma "substituição das categorias marxistas pelas figuras do direito" (NAVES, 2009, p. 27).

De maneira instigante, porém, vemos Stutchka fundamentar sua compreensão sobre um "direito revolucionário" quando as formas abstratas - para ele, tribunal, leis e decretos encontram-se na vanguarda dos fatos sociais, ou seja, têm por pauta "o sistema revolucionário no seu conjunto" (STUCKA, 1988, p. 142), entendido como "direito soviético". Neste caso, o direito perde seu sentido próprio e essencial, aquele encontrado em Marx, e adquire a dimensão pedagógica, a ponto de se prever a sua necessária popularização, para se tornar "acessível a todos": "o direito proletário é, antes de tudo, a simplificação e a popularização do nosso novo sistema social” (STUCKA, 1988, p. 130-131).

Sobre tal "direito proletário", Stutchka já havia se referido antes do livro de 1921. Em 1919, por exemplo, escrevera o texto Direito proletário, no qual precisou o âmbito de sua vigência, vale dizer, "apenas enquanto Direito da época de transição, Direito do período da Ditadura do Proletariado ou, então, como Direito da sociedade socialista" (STUTCHKA, 2009c, p. 35). Nesse momento, contudo e ao contrário do que escreveria dois anos depois, Stutchka ainda não concebe um exato sistema jurídico de relações sociais, mas um direito provisório, pois "as relações humanas, em um período de transição não se caracterizam certamente pela sua estabilidade", logo deveria haver "grandes reservas acerca da consolidação, por escrito, do Direito de uma época de transição" (STUTCHKA, 2009c, p. 46).

Em 1922, um ano após a primeira edição de seu mais importante livro, escreve um texto em que reafirma os limites históricos do "direito proletário enquanto direito de classe

\footnotetext{
${ }^{11}$ Nesse sentido, Stutchka chegou até a teorizar sobre a "Constituição da época de transição, a Constituição da Guerra Civil - tal como eu a chamaria” (STUTCHKA, 2009a, p. 27).
} 
sem maquilagem", sendo que, "no grau mais extremo, ele é um direito revolucionário, que, de nenhuma forma, levanta uma pretensão existencial maior do que a do período de transição" (STUTCHKA, 2009d, p. 78). Talvez aqui tenha ficado mais evidenciado do que em A função revolucionária do direito e do estado o seu compromisso analítico que faz conviver a transitoriedade do direito de classe com um sistema ou ordem (ou ainda ordenamento) de relações jurídicas, as quais não podem ser confundidas com seus “atributos”, as normas ou "proposições jurídicas” (STUTCHKA, 2009d, p. 72).

Sendo assim, o que permanece da proposta de Stutchka? O seu direito de transição surge como alternativa para o fato da subsistência do jurídico após a ruptura revolucionária. Abre-se, então, um caminho para o uso do direito entendido como algo mais que normas e justiça, pois relações sociais. No entanto, continua fechado o caminho para se resolver o problema de qual a essência do direito (que apenas Pachukanis resolveria). A "legalidade revolucionária" (STUCKA, 1988, p. 133) da qual falava Stutchka tem, então, as qualidades e os defeitos da forma legal que Marx enunciou, mas com o adendo de uma caracterização revolucionária: é índice de preservação da existência das classes (e da luta entre elas, o que é o mais importante aqui), mas também é dispositivo de desarme do uso fatalista do direito, vinculando-se a uma dimensão tática, já que "a transição para uma sociedade nova, sem classes, é certamente impossível sem o elemento da coerção e da persuasão" (STUCKA, 1988, p. 66), estes últimos modeladores da "dupla função" (STUCKA, 1988, p. 61) do estado.

Em resumo, a existência de uma legalidade revolucionária indica que a transição é processo longo e que, portanto, não deixa de ter sua estrutura fundada nas relações capitalistas, mas que, ao mesmo tempo, permite a saída do imobilismo e indica um uso tático revolucionário do direito, o qual, em grande parte, tem feições pedagógicas, como Lênin dava a entender (Cf. VARGA, 2012).

E a coerência do pensamento de Stutchka reside no fato de ter defendido que assim como "deveria haver um tipo especial de estado de transição, deveria haver também um particular tipo de direito" (STUCKA, 1988, p. 157). Mais de cem anos depois da revolução russa, fica o ensinamento para as novas gerações de marxistas de que, por um lado, é preciso haver dedicação não secundária para se entender este fenômeno típico do capitalismo que é o direito, mas, por outro, é preciso também estar preparado para uma práxis concreta que lide com o fenômeno jurídico como algo inevitável, dentro da ordem capitalista e mesmo em eventuais momentos de transição para outro tipo de organização societal, mas também como 
algo superável. E o legado de Stutchka, contribui, até mais que o de Pachukanis, nesse último sentido. Eis o que o estudo da cultura jurídica soviética revolucionária proporciona para todos os interessados, hoje.

\section{Referências}

BENSAÏD, Daniel. Marx, o intempestivo: grandezas e misérias de uma aventura crítica (séculos XIX e XX). Tradução de Luiz Cavalcanti de M. Guerra. Rio de Janeiro: Civilização Brasileira, 1999.

CERRONI, Umberto. "Introduzione”. Em: STUCKA, Pëtr I. La funzione rivoluzionaria del diritto e dello stato e altri scritti. Traduzione de Umberto Cerroni. Torino: Giulio Einaudi, 1967, p. XI-XLVI.

. O pensamento jurídico soviético. Lisboa: Europa-América, 1976.

FERREIRA, Adriano de Assis. Questão de classes: direito, estado e capitalismo em Menger, Stutchka e Pachukanis. São Paulo: Alfa-Ômega, 2009.

JIMÉNEZ DE ASÚA, Luis. Derecho penal soviético. Buenos Aires: TEA, 1947.

LENIN. Obras completas. Moscú: Progreso, tomo 38, 1986.

Obras completas. Moscú: Progreso, tomo 50, 1988a.

Obras completas. Moscú: Progreso, tomo 52, 1988 b.

LUKÁCS, Gyorgy. Ontologia do ser social: os princípios ontológicos fundamentais de Marx. Tradução de Carlos Nelson Coutinho. São Paulo: Ciências Humanas, 1979.

MARX, Karl. Contribuição à crítica da economia política. Tradução de Florestan Fernandes. 2 ed. São Paulo: Expressão Popular, 2008.

"Introdução (1857)". Em: . Grundrisse - Manuscritos econômicos de 18571858: esboços da crítica da economia política. Tradução de Mario Duayer, Nélio Schneider, Alice Helga Werner e Rudiger Hoffman. São Paulo: Boitempo, 2011.

MASCARO, Alysson Leandro. "Pachukanis e Stutchka: o direito, entre o poder e o capital". Em: NAVES, Márcio Bilharinho (org.). O discreto charme do direito burguês: ensaios sobre Pachukanis. Campinas: IFCH/UNICAMP, 2009, p. 45-52. 
NAVES, Márcio Bilharinho. "Stalinismo e capitalismo". Em: (org.). Análise marxista e sociedade de transição. Campinas: IFCH/UNICAMP, 2005, p. 57-73.

NEGRI, Antonio. O poder constituinte: ensaio sobre as alternativas da modernidade. Tradução de Adriano Pilatti. Rio de Janeiro: DP\&A, 2002.

PACHUKANIS, Evgeny Bronislavovitch. "The Soviet State and the Revolution in Law". Em: BABB, H. W.; HAZARD, J. N. (orgs.). Soviet Legal Philosophy. Cambridge: Harvard University Press, 1951.

PAZELLO, Ricardo Prestes. Direito insurgente e movimentos populares: o giro descolonial do poder e a crítica marxista ao direito. Curitiba: Programa de Pós-Graduação (Doutorado) em Direito da Universidade Federal do Paraná, 2014.

RUKOVODYASHCHIYE Nachala Po Ugolovnomu Pravu R.S.F.S.R. Disponível em: <http://pravo.levonevsky.org/baza/soviet/sssr7311.htm>. Data de acesso: 15 de jul. de 2013.

STUCKA, Pëtr I. "Diritto-Legge-Tecnica". Em: La funzione rivoluzionaria del diritto e dello stato e altri scritti. Traduzione de Umberto Cerroni. Torino: Giulio Einaudi, 1967a, p. 493-499.

. "Rivoluzione e legalità rivoluzionaria". Em: . La funzione rivoluzionaria del diritto e dello stato e altri scritti. Traduzione de Umberto Cerroni. Torino: Giulio Einaudi, 1967b, p. 50-511.

_. "Tre fasi del diritto sovietico". Em: . La funzione rivoluzionaria del diritto $e$ dello stato e altri scritti. Traduzione de Umberto Cerroni. Torino: Giulio Einaudi, 1967c, p. 449-455.

. "Il cosiddetto diritto sovietico". Em: La funzione rivoluzionaria del diritto $e$ dello stato e altri scritti. Traduzione de Umberto Cerroni. Torino: Giulio Einaudi, 1967d, p. 424-432.

STUCKA, Petr Ivanovich. Direito e luta de classes: teoria geral do direito. Tradução de Silvio Donizete Chagas. São Paulo: Acadêmica, 1988.

STUTCHKA, Piotr. "A constituição da guerra civil". Em: . Direito de classe $e$ revolução socialista. Tradução de Emil von München. 3 ed. São Paulo: Instituto José Luís e Rosa Sundermann, 2009a, p. 27-33. 
. "Decreto n. 1 sobre o tribunal de 24 de novembro de 1917". Em: . Direito de classe e revolução socialista. Tradução de Emil von München. 3 ed. São Paulo: Instituto José Luís e Rosa Sundermann, 2009b, p. 93-96.

. "Direito proletário". Em: . Direito de classe e revolução socialista. Tradução de Emil von München. 3 ed. São Paulo: Instituto José Luís e Rosa Sundermann, 2009c, p. 3557. . "O problema do direito de classe e da justiça de classe". Em: . Direito de classe e revolução socialista. Tradução de Emil von München. 3 ed. São Paulo: Instituto José Luís e Rosa Sundermann, 2009d, p. 59-92.

_. "Tribunal velho e tribunal novo". Em: . Direito de classe e revolução socialista. Tradução de Emil von München. 3 ed. São Paulo: Instituto José Luís e Rosa Sundermann, 2009e, p. 11-26.

VARGA, Csaba. "Lenin e a criação revolucionária do direito”. Tradução de Jair Pinheiro. Em: Novos rumos. Marília-SP: UNESP, v. 49, n. 2, julho-dezembro de 2012, p. 59-68. 